Family Profile No. 21, 2020

\title{
Marriage: More than a Century of Change, 1900-2018
}

Author: Valerie Schweizer

Although the U.S. marriage rate has dropped dramatically over the past few decades, the rate and magnitude of the decline varies across demographic groups. Using data from the National Vital Statistics, Decennial Censuses, and the American Community Survey, this profile charts marriage patterns since 1900 for women aged 15 and older. It also includes more detailed information disaggregated by race/ethnicity and educational attainment. This profile is an update of FP-18-17 and FP-13-13.

Change in the Marriage Rate in the U.S., 1900-2018

- The marriage rate in 2018 (31.3 women married in the last year per one thousand unmarried women) had fallen by more than half compared with 1900 (68.2).

- The marriage rate peaked at 92.3 in 1920 , which was nearly three times the rate in 2018.

- The marriage rate decreased steadily from 1970 to 2010 but has since stabilized.

Change in Marital Status, 1900-2018

Figure 2. Current Marital Status of Women, 1900-2018

- Married Separated/Divorced

- Widowed

Never Married

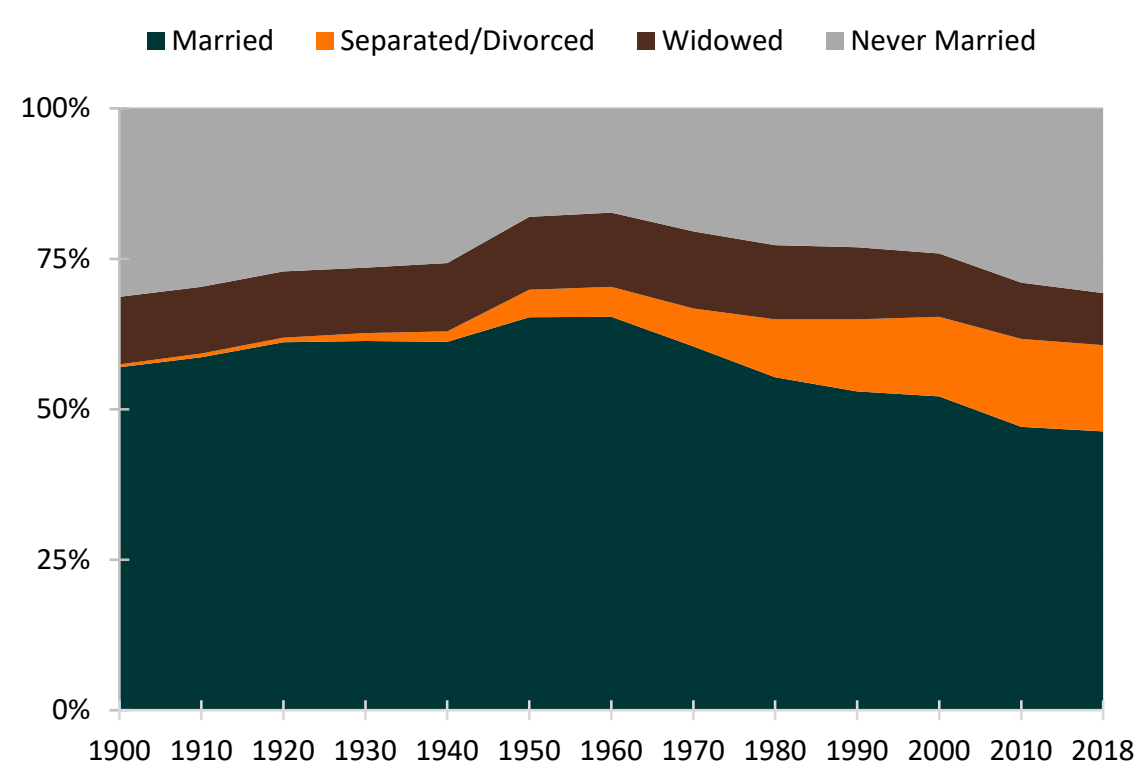

Source: NCFMR analyses of U.S. Census Bureau, Decennial Census, 1900-2010 (IPUMS); U.S. Census Bureau, American Community Survey, 2018 (IPUMS) Note: Data for separated were not available until 1950.
Figure 1. Women's Marriage Rate, 1900-2018

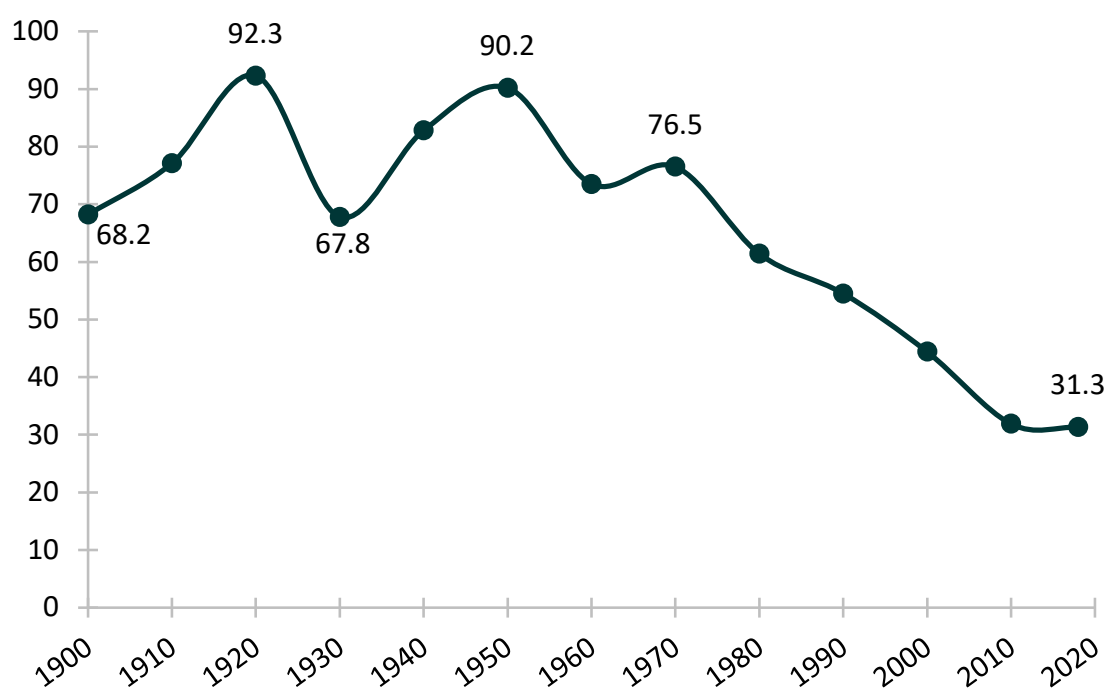

Sources: NCFMR analyses of data from the National Vital Statistics, CDC/NCHS, 1900-2000; U.S. Census Bureau 2000 Decennial Census; U.S. Census Bureau (IPUMS), American Community Survey, 2010 and 2018 (IPUMS). Note: Data for Alaska begin in 1959. Data for Hawaii begin in 1960.
- Since peaking at $65 \%$ in 1960 the percentage of women who were currently married (including those in a remarriage) has decreased to $46 \%$ in 2018.

- Since 1960, the share of women who were currently separated or divorced increased from about $5 \%$ to $14 \%$ in 2018 . For more information on separated and divorced women, see FP-20-22 (forthcoming).

- The proportion of women who were currently widowed remained stable since 1900 , with a slight decrease since 1970. For more information on widowed women, see FP-20-23 (forthcoming).

- The percentage of women who were never married was the same in 2018 as it was in 1900 (31\%). It reached its lowest percentage in 1960 when only $17 \%$ of women were never married. 
Variation in Percentage Currently Married According to Race and Ethnicity, 1940-2018

- In 1940 , about $60 \%$ of women were married regardless of race or ethnicity.

- By 2018, the percentage of women who were currently married had declined among all racial and ethnic groups except Asian women.

- The percentage of Asian women who were married has remained the most stable since 1940. In 2018, 58\% were currently married compared to $57 \%$ in 1940 .

- The most dramatic drop in the share currently married was observed among Black women. In 2018, only about one-quarter (26\%) of Black women reported being currently married.

- In 2018, the percentage of Hispanic and Other women who were married dropped to their lowest levels, at $43 \%$ and $38 \%$, respectively.

- Since 1940, the percentage of White women who were married dropped ten percentage points to $51 \%$.

Figure 3. Percentage of Women Currently Married Among Racial/Ethnic Groups, 1940-2018

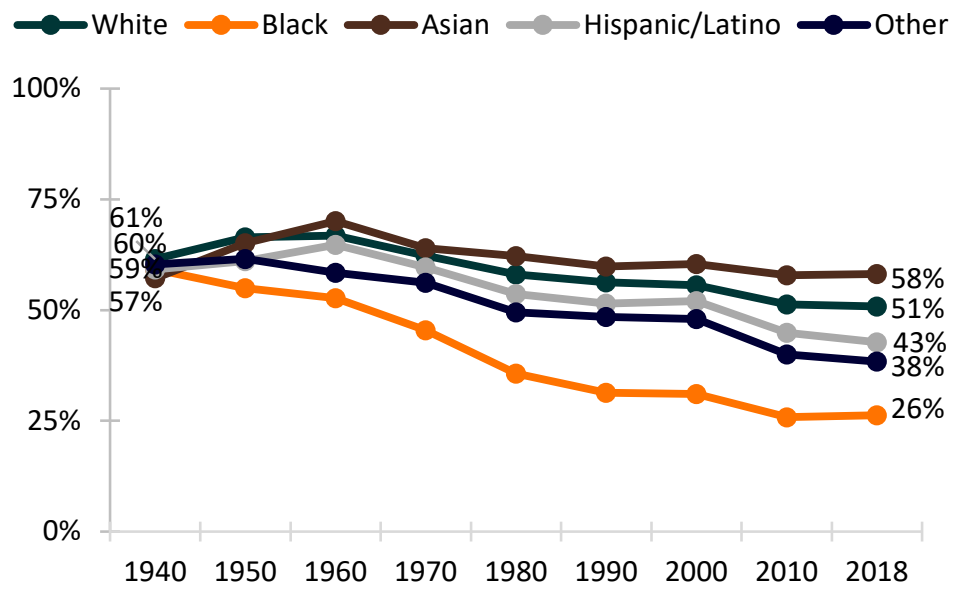

Source: NCFMR analyses of U.S. Census Bureau, Decennial Census, 1900-2010 (IPUMS); U.S. Census Bureau, American Community Survey, 2018 (IPUMS)

\section{Variation in Percentage Currently Married According to Educational Attainment, 1940-2018}

Figure 4. Percentage of Women Currently Married Among Educational Attainment Groups, 1940-2018

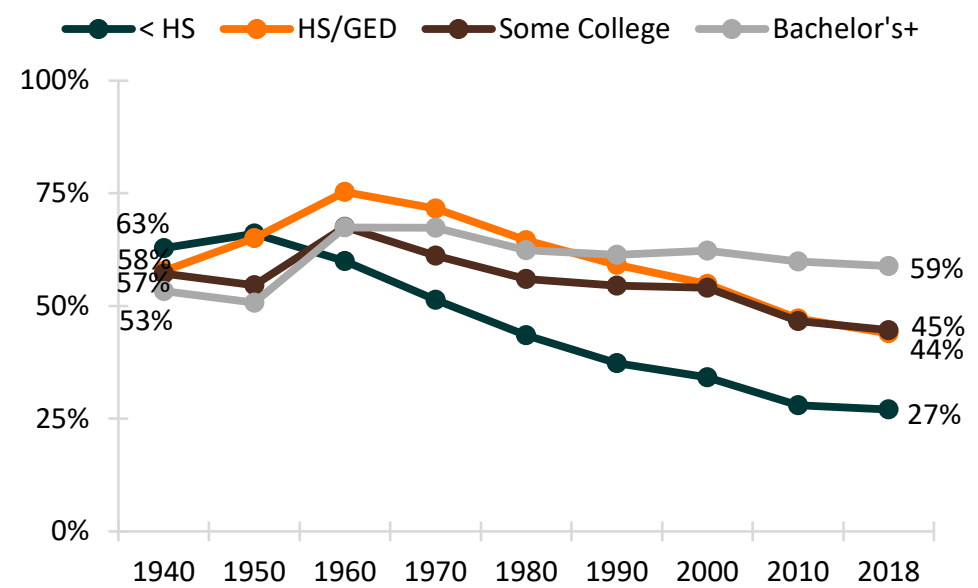

Source: NCFMR analyses of U.S. Census Bureau, Decennial Census, 1900-2010 (IPUMS); U.S. Census Bureau, American Community Survey, 2018 (IPUMS)
- In 1940 , between $53 \%$ and $63 \%$ of women in all educational attainment groups were married.

- By 2018, the percentages of women who were married had diverged across education groups.

- Only $27 \%$ of those with less than a high school education in 2018 were married.

- Those with a high school education and with some college education have converged in recent decades, and both continue to decline with $44 \%$ and $45 \%$ married in 2018 , respectively.

- The percentages of college graduates who were married has remained steady over the last 35 years, with $59 \%$ in 2018.

\section{Data Source:}

Plateris, A. A. (1973). 100 Years of Marriage and Divorce Statistics United States, 18671967. National Center for Health Statistics. Vital and Health Statistics. Series 21: Data from the national vital statistics system. Data on natality, marriage, and divorce, no. 24; DHEW publication no. (HRA) 74-1092. Retrieved from https://stacks.cdc.gov/view/cdc/12831

Ruggles, S., Flood, S., Goeken, R., Grover, J., Meyer, E. Pacas, J., \& Sobek, M. (2020). IPUMS USA: Version 10.0 [dataset]. Minneapolis, MN: IPUMS, 2020. https://doi.org/10.18128/D010.V10.0

Centers for Disease Control and Prevention, National Center for Health Statistics. Monthly Vital Statistics Reports. Retrieved from https://www.cdc.gov/nchs/products/mvsr.htm\#43_12s
References:

Allred, C. A. (2018). Marriage: More than a century of change, 1900-2016. Family Profiles, FP-18-17. Bowling Green, OH: National Center for Family \& Marriage Research. https://doi.org/10.25035/ncfmr/fp-18-17.

Carlson, L. \& Schweizer, V. J. (2020). Widowhood: Decades of change. Family Profiles, FP-20-23. Bowling Green, $\mathrm{OH}$ : National Center for Family \& Marriage Research. https://doi.org/10.25035/ncfmr/fp-20-23

Cruz, J. (2013). Marriage: More than a century of change. Family Profiles, FP-13-13. Bowling Green, $\mathrm{OH}$ : National Center for Family \& Marriage Research. https://www.bgsu.edu/content/dam/BGSU/college-of-arts-andsciences/NCFMR/documents/FP/FP-13-13.pdf.

Schweizer, V. J. (2020). Divorce: More than a century of change. Family Profiles, FP-2022. Bowling Green, $\mathrm{OH}$ : National Center for Family \& Marriage Research. https://doi.org/10.25035/ncfmr/fp-20-22

\section{Suggested Citation:}

Schweizer, V. J. (2020). Marriage: More than a century of change. Family Profiles, FP-20-21. Bowling Green, OH: National Center for Family \& Marriage Research. https://doi.org/10.25035/ncfmr/fp-20-21

B O W L I N G G R E E N S T A t E U N I v E R s I T Y
This project is supported with assistance from Bowling Green State University. From 2007 to 2013, support was
the U.S. Department of Health and Human Services, Office of the Assistant Secretary for Planning and Evaluation. The opinions and conclusions expressed herein are solely those
of the author(s) and should not be construed as representing the opinions or policy of any agency of the state or federal government.

